\title{
The Method of the Basic Computer Technology Instruction and Its Application
}

\author{
Xueming Jia \\ Information Security College, Yunnan Police College \\ Kunming 650223, P.R. China \\ 56784770@qq.com
}

Keywords: Computer instruction; Instruction strategy; Big data

\begin{abstract}
With the development of the information technology and the data analysis, the traditional instruction method for the basic computer technology instruction should be improved in order to enhance the corresponding instruction efficiency. In this paper, the current problem of the computer technology instruction is discussed firstly. Then the corresponding methods that how to enhance the efficiency is proposed. Based on our conclusion, the proposed method is indeed an efficient way to achieve our instruction objective.
\end{abstract}

\section{Introduction}

The basic computer technology instruction (computer technology is abbreviated in the last paper) is one of most important courses for all of the college student. Most researches focus on the point that how to enhance the instruction efficiency of this course, such as [1-3]. However, under the case that the big data is widely used in every field, the objective or the methods of the computer technology course is also changed. Predecessors' work figure out that the current course instruction is different from the ways during any other times [4-6]. In this case, it is necessary to find a efficient way to improve the instructing method for the computer technology course. In this paper, we aim to discuss a reasonable method to enhance the efficiency of the instruction.

Course is the required public basic course for non-computer majors in colleges and universities, one of by learning this course and make the students be able to use computers to improve their own learning and work efficiency, also for the future use computer knowledge to solve actual problem to lay a solid foundation of professional. But at present, the public security colleges and universities the university computer foundation course teaching content and methods can not fully meet the needs of reality, as the whole society to the improving of the college students' computer application ability level requirements, university computer foundation course teaching is also facing a new round of deepening reform, the formidable task of improving the quality of computer basis teaching effectively. How to seek the teaching reform has become an important topic facing the university computer foundation teaching.

\section{The Problem Description}

Firstly, students do not pay more attention to the computer technology course. Some students think they will shallow movies playing games, chatting online is mastered the use of computers, cognitive limitations; Some students think they learned in high school, such as information technology knowledge, the university don't have to learn this course, have different understanding. More students think that as long as the professional courses to learn, learn not learn computer foundation course are all well doesn't matter, cognitive deviation; In addition, there are a few lectures of this course teachers realize the importance of this course is also insufficient, think for non-computer majors, this course is not students' professional 
class, the teacher tell me the students to learn the simple, it also led to the part of students' learning enthusiasm is not point of interest is not big.

Secondly, Students holds various levels of computer technology. There are gaps in education unbalanced development, which leads to the students. Thanks to the rapid popularization of computer education for nearly ten years, basic computer education is not only the university education content, high school and even elementary school has spread at different levels. But owing to different regional economic conditions, the development is not balanced, the graduate school of computer knowledge difference is bigger, some developed areas, large and medium-sized cities to students of the computer knowledge level has reached the computer culture basic course teaching requirements stipulated by the state. And from remote areas, economic underdeveloped regions in quite a few students hardly used computers, computer basic is zero. On different students accept ability understanding ability of computer knowledge, there are certain differences, if for all students to use unified teaching syllabus and the teaching content, want to seek a suitable for the majority of students learning of this course teaching mode is difficult to achieve, this has led to the foundation of good students are not interested in the teacher's teaching content, that they can't concentrate in class, and even truancy absenteeism, and the basis of poor students and the teacher teach content and unable to understand and grasp all operation, which makes it impossible to complete the teaching plan, teaching effect is also difficult to achieve goals. Therefore, facing the university computer foundation teaching how to do is different from person to person, according to their aptitude.

Third, the objective of the instruction is fuzzy. On computer education is the only method, means and skills training, or an important part of the professional training goal is not clear. The idea that university computer foundation course teaching content is "simple operations and software tools to use", "computer program design" is the ideas and opinions [1], has far lagging behind the modern information society development and needs, this kind of misunderstanding caused on the university computer foundation course teaching content updates slowly, lagged behind the development of computer hardware and software; Teaching requires that acted on random reduce university computer foundation teaching training goals and objectives.

\section{Methods}

One efficient method to tackle these problems is to set the computational thinking as the objective of instructions. We will discuss how to implement this in details as follows:

Training the Computational Thinking of Students. With the development of the computer technology, the requirement of the computer skill for graduating student become striker and striker. The instructions of the computer technology should aim to train the basic skill that the student use the computer to resolve the exact problem. However, in today, the big data change the thinking pattern which is different from thinking methods during any other times in the past. In this case, the objective of the corresponding instruction should be suit for these requirements. As well, the popular computational thinking is the one needed to be faced.

Developing the Content of Course. Computational thinking is aimed at helping them to use the college students, the basic idea of computational thinking method system research and the basic theory of learning computer knowledge, and apply it to solve the problem of all kinds of professional practice. Therefore, the courses which aim to instruct the corresponding students should be changed to promote the efficiency of instructions. However, to evaluate the instructing efficiency is difficult, Although the objective of instructions is to promote the ability of the computational thinking.

Training the Ability That the Graduating Students Use the Computer to Resolve Problems. Computational thinking represents the people of a common understanding and the ability of a kind of universal, is not only a computer scientist, but everyone should be eager to learn and to use it .In order to make students can quickly will calculate thinking applied to practical problems in processing, mainly 
adopts the following method to organize teaching. First to calculate the course of thinking as the platform, through teaching the students master the basic knowledge of computer science and comprehensive system of computational thinking ideas at the same time, applying the teaching emphasis to calculate thinking to deal with specific problems, explore the universal applicable to general processing problems through practice thinking, gradually formed the calculation methods and computer technology to handle the problem correctly. Such as in the teaching of "information and the data processing" content, because it involves many technical details, therefore, teachers in teaching should avoid entanglement of the implementation details, emphasis on dealing with problems by thinking.

\section{Measures}

In order to enhance the efficiency of the instructions of the computer technology course. Some efficient measures are proposed in this section.

Firstly, the structure of the instructions which aims to enhance the efficiency of the computer technology should be constructed. Furthermore, the structure for the experimental instruction should be constructed firstly. Experiment practice teaching system structure reform is to improve the core of the reform of the university computer foundation teaching quality measures, as an important carrier to develop the innovative ability of thinking and the suggestion, according to the principle of "generally give attention to two or more things, outstanding characteristic" organization and arrangement of experiment teaching. First of all, to consolidate students' mastery of knowledge units, teaching can arrange some can not only reflect the computer basic knowledge, basic principle, can reflect computational thinking and the basic thought and method of experiment content, on the choice of subject matter as far as possible close to life, and must have a lot of fun, cause students interest and participation in the initiative, through experiment verifies the correctness of the theoretical knowledge and the scientific nature and operability, help students understand the universal thinking in the teaching of experiment. Second, to meet the different characteristics of professional and disciplinary research needs, develop and find out the creative potential of students, can add some appropriate class has a process to explore and diversified comprehensive innovation content, aimed at a targeted to improve students' ability of using computational thinking abstraction and analysis problem, gradually formed to solve the problem of general and universal mind, finally applied to the processing various kinds of professional and scientific research.

Secondly, the WEB site which is used for instruction will be constructed more powerfully. To better cooperate with the university computer foundation teaching reform, more open and autonomous learning space for students, colleges and universities should further intensify the integration of teaching resources and the construction. In addition to continue to improve the classroom, reading room, etc have type entity space utilization, should make full use of network space advantages, vigorously develop the service of all kinds of teaching website, to expand the application of the virtual space in the teaching process.

Thirdly, To enhance the creative ability of the graduating students. For the calculation of thinking as the core of teaching reform to implement real, must vigorously strengthen the construction of the examination system the connotation of the knowledge base. Construction should focus on most of the students to understand and master basic computer basic knowledge, on the basis of focusing on cultivating students' understanding and mastering the system from the perspective of nature and the global basic principle and method of use, gradually formed the calculation methods of right thinking to solve the problem. Assessment of key location in enhance students' comprehensive ability in using computer processing actual problem. 


\section{Conclusions}

We must constantly sum up experience in the process of teaching, further deepen the reform, to establish a rigorous curriculum system, using modern education technology platform, the basic computer teaching on a new level, we need to actively explore and access to university computer foundation course teaching reform experience, we need to continue to research and practice, we need to act quickly, to promote the further development of reform of university computer foundation, only in this way, can adapt to the talent of the 21 st century, to be able to catch up with the advanced world level, not the historical mission of education reform.

\section{Acknowledgement}

This work is supported by Educational Science Foundation of Yunnan Province under Grant (2014YESK-03) and by Natural Science Foundation of Yunnan Province under Grant (2013FD042).

\section{References}

[1] Enhancing Teaching and Learning through Education Data Mining and Learning Analytics [J], Education Department of America, 2012, 336-339.

[2] Brynjolfsson, E. Erik Brynjolfsson on Big Data: A Revolution in Decision -- Making Improves Productivity [EB/OL]. http://mitsloanmit. Edu /erik -- brynjolfsson.

[3] Lee, YH, Hsieh, Y, Adding Innovation Diffusion Theory to the Technology Acceptance Model: porting Employees' Intentions to use E-Learning Systems [J] . Educational Technology\& Society,14 (4), 2011:124-137

[4] Bapler. P \& Murdoch, Academic Analytics on Data Mining in Higher Education. Intemational Jounlal for the Scholarship of Teaching and Leanling [C], 4(2), 2013, 1926-1933.

[5] Y. Zhu, etc, The innovation of the basic computer instruction under the computational thinking, Journal of Shenyang Agricultural University, 2014-05, 16(3): 338-341

[6] GuoLiang Chen, etc, The innovation of the university to calculate the revitalization of education science and engineering research, [EB/OL] (2011-12-22)

http://blog.sciencenet.cn/blog-512355-520901.html. 